\title{
Genetic variants of MCP-1 and CCR2 genes and IgA nephropathy risk
}

\author{
Jie Gao ${ }^{1, *}$, Xinghan Liu ${ }^{2, *}$, Linting Wei ${ }^{1, *}$, Dan Niu ${ }^{3}$, Jiali Wei ${ }^{4}$, Li Wang ${ }^{1}$, Heng $\mathrm{Ge}^{1}$, \\ Meng Wang ${ }^{2}$, Qiaoling Yu ${ }^{5}$, Tianbo Jin ${ }^{6}$, Tian Tian ${ }^{2}$, Zhijun Dai $^{2}$, Rongguo Fu ${ }^{1}$ \\ ${ }^{1}$ Department of Nephrology, Second Affiliated Hospital of Xi'an Jiaotong University, Xi'an 710004, China \\ ${ }^{2}$ Department of Oncology, Second Affiliated Hospital of Xi'an Jiaotong University, Xi'an 710004, China \\ ${ }^{3}$ Department of Nephrology, First Affiliated Hospital of Xi'an Jiaotong University, Xi'an 710061, China \\ ${ }^{4}$ Department of Nephrology, Hainan general hospital, Haikou 570311, China \\ ${ }^{5}$ Department of Pathology, Second Affiliated Hospital of Xi'an Jiaotong University, Xi'an 710004, China \\ ${ }^{6}$ National Engineering Research Center for Miniaturized Detection Systems, School of Life Sciences, Northwest University, \\ Xi'an 710069, China \\ "These authors have contributed equally to this work \\ Correspondence to: Jie Gao, email: gxej_cn@sina.com \\ Rongguo Fu, email: pipifu@126.com \\ Keywords: monocyte chemoattractant protein-1, IgA nephropathy, polymorphism, risk, case-control study \\ Received: September 16,2016 Accepted: October 12, $2016 \quad$ Published: October 24, 2016
}

\section{ABSTRACT}

Monocyte chemoattractant protein-1 (MCP-1) and its receptor CCR2 stimulate inflammation response by activating and recruiting monocytes/macrophages. MCP-1 and CCR2 polymorphisms were reported to be associated with various diseases. To explore the relationship between MCP-1 and CCR2 polymorphisms and IgA nephropathy (IgAN), we conducted this case-control study by enrolling 351 IgAN patients and 310 health controls. Odds ratios (ORs) and $95 \%$ confidence intervals (CIs) were calculated to evaluate potential associations of MCP-1 and CCR2 polymorphisms with susceptibility and clinical parameters of IgAN. No statistical differences between IgAN group and the control group in the MCP-1 -2518 and CCR2 +190 genotypic groups were observed ( $P$ $>0.05$ ). Individuals with MCP-1 $-2518 \mathrm{GG}$ genotypes had a higher blood pressure (GG vs. AA+AG: $O R=1.79,95 \% C I=1.07-2.99, P=0.026$ ) and Lee's grade (GG vS. AA+AG: OR $=2.05,95 \%$ CI $=1.19-3.54, P=0.009 ;$ GG vs. $A A:$ OR $=2.24,95 \%$ CI $=1.19-4.20$, $P=0.01)$, compared with patients with AA/AG genotypes. A significant association between CCR2 +190 polymorphism and Lee's grades was observed (GA+AA vs. GG: OR $=2.66,95 \% \mathrm{CI}=1.63-4.35, P<0.001 ;$ GA vs. $\mathrm{AA}+\mathrm{GG}$ : $\mathrm{OR}=2.27,95 \% \mathrm{CI}=1.39-3.70$, $P=0.001)$. Our results indicated that MCP-1 and CCR2 polymorphisms may influence the progression of IgAN, but not increase/decrease its susceptibility.

\section{INTRODUCTION}

IgA nephropathy ( $\operatorname{IgAN})$, which is also called Berger's disease, is the most frequent glomerulonephritis characterized by the deposition of IgA1-based immune complexes in mesangium $[1,2]$. Although some new biomarkers exist, renal biopsy is the gold standard for the diagnosis of IgAN [3]. Proteinuria and hematuria were the main clinical manifestations for IgAN and increasing proteinuria usually associated with worse clinicopathologic features in IgAN patients $[4,5]$. IgAN patients with mild symptoms often coincide with an upper respiratory tract infection at initial, but $50 \%$ of these patients will develop into end-stage renal disease within the next 20 years [6]. Air pollution, low socioeconomic status, and gene are the risk factors for IgAN [7]. In a test including 148 healthy female twins, the heritability of serum undergalactosylated IgA1 and IgA levels were found to be $80 \%$ and $46 \%$, respectively, which indicates the importance of genetic factors in pathogenesis of IgAN [8]. Genome-wide association studies also reported polymorphisms in gene were strongly correlated with IgAN prevalence and prognosis, but the associations and the magnitude are needed to confirm $[9,10]$. 
Monocyte chemoattractant protein-1 (MCP-1), which is also known as C-C chemokine ligand 2 (CCL2), promotes the recruitment of monocytes, macrophages, and other inflammatory cells to inflammation site by interaction with its receptor CCR2 [11]. In MCP-1-intact mice models, MCP-1 was mainly localized in cortical tubules and induced tubular injury by recruiting macrophages [12]. MCP-1 plays a vital role in the progression of renal diseases. Liu et al. found human serum albumin could stimulate proximal tubular epithelial HK-2 cells to produce MCP-1, and the effect was obvious when its concentration was more than $2 \mathrm{~g} / \mathrm{L}$ [13]. Sun et al. suggested a positive association between MCP-1 in tubulointerstitial and $24 \mathrm{~h}$ urinary protein excretion, which indicated high urinary protein in IgAN patients may stimulate the expression of MCP-1 and further promote and activate monocytes/macrophages, finally leading to renal injury and interstitial fibrosis [14]. CCR2 is the specific receptor of MCP-1, and the MCP-1/CCR2 signal axis was involved in the transmission of cell information and cell migration, which could enhance cell proliferation and migration ability of renal cell carcinoma by autocrine [15]. High expression of MCP1 and CCR2 were significantly associated with shortened survival time and increased risk of recurrence in patients carrying non-metastatic clear-cell renal cell carcinoma and CCL2/CCR2 signature had a negative effect on overall survival and recurrence-free survival [16]. In view of the correlation between MCP-1 and CCR 2 and their synergistic effect in biological function, there were a large number of researches focused on their SNPs together [11, 17-19], in order to find a meaningful haplotype combination. A previous study by Mandal et al. stated that MCP-1 -2518A/G and CCR2 +190 G/A polymorphisms had a synergistic relationship [11].

Recent articles have reported the association between MCP-1 and CCR2 gene polymorphisms and various diseases. A meta-analysis indicated MCP-1 $-2518 \mathrm{~A} / \mathrm{G}$ polymorphism was significantly associated with lupus nephritis occurrence in Caucasians [20]. MCP1 -2518AA genotype was a risk for diabetes mellitus patients developing into diabetic nephropathy [21]. CCR2 $+190 \mathrm{G} /$ A polymorphism had no association with diabetic nephropathy in Japanese [22]. Only one article evaluated the association between MCP-1 -2518A/G polymorphism and primary glomerulonephritis, but the authors failed to find any correlation in the Polish population [23].

Till now, few studies had investigated the association of MCP-1 -2518A/G and CCR2 +190G/A polymorphisms with IgAN susceptibility, but the results were inconsistent. Therefore, we conducted this case-control study to evaluate the association in the Chinese population.

\section{RESULTS}

\section{Characteristics of the participants}

We recruited 351 IgAN patients as the case group and 310 health persons as the control group. The characteristics of the two groups were listed in Table 1. The average age in cases and controls had no statistical difference $(32 \pm 11.9$ vs. $35 \pm 12.6, P=0.45) .65 \%$ of the patients and $60 \%$ of the health were male $(P=0.16)$. The frequencies of patients that had a $24 \mathrm{~h}$ urine protein $<3.5 \mathrm{~g} / 24 \mathrm{~h}$, blood pressure $<140 / 90 \mathrm{mmHg}$, and I+II + III Lee's classifications were $77.5 \%, 55.3 \%$, and $74.1 \%$, respectively. The average of serum creatinine, blood urea nitrogen, serum albumin, IgA, and C3 levels were $159.5 \pm 146.0$ umol/L, $8.2 \pm 5.9 \mathrm{mmol} / \mathrm{L}, \quad 34.01 \pm 7.98$ $\mathrm{g} / \mathrm{L}, 2.76 \pm 1.72 \mathrm{~g} / \mathrm{L}$, and $1.06 \pm 0.26 \mathrm{~g} / \mathrm{L}$, respectively. The genotypes of MCP-1 -2518 and CCR2 +190 polymorphisms in the control group were in HardyWeinberg equilibrium ( $P=0.34$ and 0.95 , respectively).

\section{Associations between genotype frequencies and IgAN risk}

As shown in Table 2, MCP-1-2518 AG genotype decreased the IgAN risk to 0.90 and GG genotype increased the IgAN risk to 1.20 compared with AA genotype, but there was no statistical difference (AG vs. $\mathrm{AA}: \mathrm{OR}=0.90,95 \% \mathrm{CI}=0.64-1.26, P=0.53$; $\mathrm{GG}$ vs. $\mathrm{AA}: \mathrm{OR}=1.20,95 \% \mathrm{CI}=0.78-1.85, P=0.40$ ). The $P$ values were also not significant in other comparisons (Dominant model: $\mathrm{OR}=0.98,95 \% \mathrm{CI}=0.72-1.35$, $P=0.91$; Recessive model: $\mathrm{OR}=1.28,95 \% \mathrm{CI}=0.86-$ $1.88, P=0.22$; Overdominant model: $\mathrm{OR}=0.84,95 \%$ $\mathrm{CI}=0.62-1.15, P=0.27$; Log-additive model: $\mathrm{OR}=$ $1.06,95 \% \mathrm{CI}=0.86-1.31, P=0.56)$. The GG, GA and AA genotype frequencies of CCR $2+190$ polymorphisms in cases were $51.8 \%, 40.5 \%$, and $7.8 \%$, and in controls were $58.4 \%, 34.2 \%$, and $7.4 \%$, respectively. We failed to find any significant association between CCR2 +190 polymorphism and the susceptibility to IgAN in any comparison (Table 3 ).

\section{Associations between genotype frequencies and IgAN clinical parameters}

To figure out if the two polymorphisms affect the progression of IgAN or have the gender difference, we investigated the correlation between the two polymorphisms and a series of indexes. According to gender, $24 \mathrm{~h}$ urinary protein $(3.5 \mathrm{~g})$, blood pressure $(140 / 90 \mathrm{mmHg})$ and Lee's grades (III), IgAN patients were divided into two groups. MCP-1 -2518 genotypes distribution had no difference between different genders or $24 \mathrm{~h}$ urinary protein of patients (Table 4). Compared with individuals with -2518 AA/AG genotypes, patients with GG genotypes had a higher blood pressure (Table 4, GG vs. AA+AG: $\mathrm{OR}=1.79,95 \% \mathrm{CI}$ $=1.07-2.99, P=0.026 ;$ GG vs. $\mathrm{AA}: \mathrm{OR}=1.85,95 \% \mathrm{CI}$ $=1.04-3.28, P=0.035$ ) and Lee's grade (Table $4, \mathrm{GG}$ vs. AA+AG: $\mathrm{OR}=2.05,95 \% \mathrm{CI}=1.19-3.54, P=0.009 ; \mathrm{GG}$ vs. $\mathrm{AA}: \mathrm{OR}=2.24,95 \% \mathrm{CI}=1.19-4.20, P=0.01)$. In male patients, CCR2 +190 GG genotype accounts for $57.6 \%$, 
Table 1: Basic characteristics of the subjects

\begin{tabular}{|c|c|c|c|}
\hline Total subjects $(n=661)$ & IgAN & Control & $\boldsymbol{P}$ \\
\hline Number of subjects (n) & 351 & 310 & \\
\hline Male/Female & $229 / 122$ & $186 / 124$ & $0.16^{\mathrm{a}}$ \\
\hline Age (mean \pm SD) & $32 \pm 11.9$ & $35 \pm 12.6$ & $0.45^{\mathrm{b}}$ \\
\hline \multicolumn{4}{|l|}{$24 \mathrm{~h}$ urine protein $(\mathrm{g} / 24 \mathrm{~h})$} \\
\hline$<3.5$ & $272(77.5 \%)$ & & \\
\hline$\geq 3.5$ & $79(22.5 \%)$ & & \\
\hline \multicolumn{4}{|l|}{ blood pressure (mmHg) } \\
\hline$<140 / 90$ & $194(55.3 \%)$ & & \\
\hline$\geq 140 / 90$ & $157(44.7 \%)$ & & \\
\hline \multicolumn{4}{|l|}{ Lee's classification } \\
\hline $\mathrm{I}+\mathrm{II}+\mathrm{III}$ & $260(74.1 \%)$ & & \\
\hline $\mathrm{IV}+\mathrm{V}$ & $91(25.9 \%)$ & & \\
\hline Serum Cr $(\mu \mathrm{mol} / \mathrm{L})$ & $159.5 \pm 146.0$ & & \\
\hline BUN (mmol/L) & $8.2 \pm 5.9$ & & \\
\hline Serum ALB (g/L) & $34.01 \pm 7.98$ & & \\
\hline Serum IgA (g/L) & $2.76 \pm 1.72$ & & \\
\hline Serum C3 (g/L) & $1.06 \pm 0.26$ & & \\
\hline
\end{tabular}

a $P$ values was calculated from two-sided chi-square test;

${ }^{\mathrm{b}} P$ values were calculated by Student $t$ tests.

Table 2: Relationships between MCP-1 -2518 polymorphism and IgA nephropathy risk

\begin{tabular}{|c|c|c|c|c|c|}
\hline Model & Genotype & Control & Case & $\begin{array}{c}\text { OR } \\
(95 \% \mathrm{CI})\end{array}$ & $P$-value \\
\hline \multirow[t]{3}{*}{ Codominant } & $\mathrm{A} / \mathrm{A}$ & $115(37.1 \%)$ & $131(37.5 \%)$ & 1.00 & \\
\hline & $\mathrm{A} / \mathrm{G}$ & $141(45.5 \%)$ & $144(41.3 \%)$ & $0.90(0.64-1.26)$ & 0.53 \\
\hline & $\mathrm{G} / \mathrm{G}$ & $54(17.4 \%)$ & $74(21.2 \%)$ & $1.20(0.78-1.85)$ & 0.40 \\
\hline \multirow[t]{2}{*}{ Dominant } & $\mathrm{A} / \mathrm{A}$ & $115(37.1 \%)$ & $131(37.5 \%)$ & 1.00 & 0.91 \\
\hline & $\mathrm{A} / \mathrm{G}-\mathrm{G} / \mathrm{G}$ & $195(62.9 \%)$ & $218(62.5 \%)$ & $0.98(0.72-1.35)$ & \\
\hline \multirow[t]{2}{*}{ Recessive } & $\mathrm{A} / \mathrm{A}-\mathrm{A} / \mathrm{G}$ & $256(82.6 \%)$ & $275(78.8 \%)$ & 1.00 & 0.22 \\
\hline & $\mathrm{G} / \mathrm{G}$ & $54(17.4 \%)$ & $74(21.2 \%)$ & $1.28(0.86-1.88)$ & \\
\hline \multirow[t]{2}{*}{ Overdominant } & $\mathrm{A} / \mathrm{A}-\mathrm{G} / \mathrm{G}$ & $169(54.5 \%)$ & $205(58.7 \%)$ & 1.00 & 0.27 \\
\hline & $\mathrm{A} / \mathrm{G}$ & $141(45.5 \%)$ & $144(41.3 \%)$ & $0.84(0.62-1.15)$ & \\
\hline Log-additive & --- & --- & --- & $1.06(0.86-1.31)$ & 0.56 \\
\hline
\end{tabular}

OR: odds ratio, 95\% CI: 95\% confidence interval.

GA+AA genotypes account for $57.6 \%$ and $35.4 \%$, which were similar to the proportion in female patients (Table 4, $\mathrm{GA}+\mathrm{AA}$ vs. $\mathrm{GG}$ : $\mathrm{OR}=1.09,95 \% \mathrm{CI}=0.70-1.71, P=0.69)$. Under all the comparison models, we did not find the relationship of CCR $2+190$ polymorphism with 24 h urinary protein or blood pressure (Table 4). However, a significant association between CCR2 +190 polymorphism and Lee's grades was observed (Table 4, GA+AA vs. GG: OR = 2.66, $95 \% \mathrm{CI}=1.63-4.35, P<0.001$; GA vs. $\mathrm{AA}+\mathrm{GG}$ : $\mathrm{OR}=$ $2.27,95 \% \mathrm{CI}=1.39-3.70, P=0.001)$. 
Table 3: Relationships between CCR2 +190 polymorphism and IgA nephropathy risk

\begin{tabular}{|c|c|c|c|c|c|}
\hline Model & Genotype & Control & Case & $\begin{array}{c}\text { OR } \\
(95 \% \mathrm{CI})\end{array}$ & $P$-value \\
\hline \multirow[t]{3}{*}{ Codominant } & $\mathrm{G} / \mathrm{G}$ & $160(51.8 \%)$ & $205(58.4 \%)$ & 1.00 & \\
\hline & $\mathrm{G} / \mathrm{A}$ & $125(40.5 \%)$ & $120(34.2 \%)$ & $0.75(0.54-1.04)$ & 0.08 \\
\hline & $\mathrm{A} / \mathrm{A}$ & $24(7.8 \%)$ & $26(7.4 \%)$ & $0.85(0.47-1.53)$ & 0.58 \\
\hline \multirow[t]{2}{*}{ Dominant } & $\mathrm{G} / \mathrm{G}$ & $160(51.8 \%)$ & $205(58.4 \%)$ & 1.00 & 0.09 \\
\hline & $\mathrm{G} / \mathrm{A}-\mathrm{A} / \mathrm{A}$ & $149(48.2 \%)$ & $146(41.6 \%)$ & $0.76(0.56-1.04)$ & \\
\hline \multirow[t]{2}{*}{ Recessive } & G/G-G/A & $285(92.2 \%)$ & $325(92.6 \%)$ & 1.00 & 0.86 \\
\hline & $\mathrm{A} / \mathrm{A}$ & $24(7.8 \%)$ & $26(7.4 \%)$ & $0.95(0.53-1.69)$ & \\
\hline \multirow[t]{2}{*}{ Overdominant } & G/G-A/A & $184(59.5 \%)$ & $231(65.8 \%)$ & 1.00 & 0.10 \\
\hline & $\mathrm{G} / \mathrm{A}$ & $125(40.5 \%)$ & $120(34.2 \%)$ & $0.76(0.56-1.05)$ & \\
\hline Log-additive & --- & --- & --- & $0.84(0.66-1.07)$ & 0.16 \\
\hline
\end{tabular}

OR: odds ratio, $95 \%$ CI: $95 \%$ confidence interval.

\section{Associations between MCP-1-2518 and CCR2 +190 haplotypes and IgAN risk}

To explore the interaction between the two polymorphisms, we further constructed the haplotype model. As shown in Table 5, comparing to $\mathrm{A}_{-2518} \mathrm{G}_{+190}$ haplotype, $\mathrm{A}_{-2518} \mathrm{~A}_{+190}$ and $\mathrm{G}_{-2518} \mathrm{~A}_{+190}$ haplotypes had no significant effect on $\operatorname{Ig} A N$ risk $\left(A_{-2518} A_{+190}\right.$ vs. $A_{-2518} G_{+190}$ : $\mathrm{OR}=0.80,95 \% \mathrm{CI}=0.64-1.02, P=0.07 ; \mathrm{G}_{-2518} \mathrm{~A}_{+190}$ vs. $\left.\mathrm{A}_{-2518} \mathrm{G}_{+190}: \mathrm{OR}=1.04,95 \% \mathrm{CI}=0.75-1.46, P=0.81\right)$.

\section{DISCUSSION}

Chemokines, with 8 to $12 \mathrm{kD}$ molecular weights, are divided into four subfamilies $(\mathrm{CXC}, \mathrm{CC}, \mathrm{C}$, and CX3C) by their N-terminal cysteine-motifs [24]. MCP1, belongs to the CC subfamily, has a strong chemotaxis and can activate the monocytes/macrophages, lead to the infiltration and activation of mononuclear cells, and the secretion of various inflammatory factors and fibrosis factors. An increased number of tubulointerstitial macrophages was significantly associated with a poor prognosis in IgAN patients [25]. Macrophages could activate nuclear factor-kappa $B(N F-\kappa B)$ and active protein-1 (AP-1), up-regulate the expression of multiple cytokines, chemokines and adhesion factors, such as tumor necrosis factor-9 and matrix metalloprotein-9, induce mesangial cell proliferation and matrix deposition, and further aggravate the kidney damage [26, 27]. NF$\kappa \mathrm{B}$ and $\mathrm{MCP}-1$ increasingly expressed in glomeruli and interstitium was correlated with progression of tissue injury in IgAN [28]. In IgAN patients, the MCP-1 level was positively correlated with $24 \mathrm{~h}$ urinary protein, renal tubular interstitial damage and serum creatinine, which indicated MCP-1 may be associated with IgAN progression [29]. IgA1 deposition, as the initiating factor in IgAN, can stimulate mesangial cells to produce MCP1 [30], which eventually leaidng to the activation and accumulation of monocytes/macrophages and contributing to renal interstitial inflammation in kidney [31], Stangou et al. found that in IgAN patients, MCP-1 was positively associated with severe extracapillary proliferation $(P$ $=0.001)$ and $\mathrm{Th} 2$ and Th17 cytokines were directly involved in renal pathology in IgAN through regulating the MCP-1 production [32]. In this study, we found MCP-1 -2518 polymorphism was related with IgAN patients' blood pressure and Lee's grades, except IgAN risk, what were consistent with the results of a previous study. Steinmetz et al. performed a case-control study with 207 IgAN patients and 140 controls, and revealed that patients with different MCP-1 -2518 genotypes had no difference in cumulative survival, median survival time or 5 year survival rate and MCP-1 -2518 polymorphism had no association with IgAN risk or clinical course [33]. However, in a study in Japan, the authors suggested that MCP-2518 AA genotype increased the risk of end stage renal disease and the progression of renal disease of IgAN patients compared with AG/GG genotype and individuals with AA genotype had a worse prognosis [34]. Different conclusions may result from ethnic difference, sample size or environmental factors.

CCR2, the receptor for MCP-1, play an important role in inflammatory disorders and some diseases $[35,36]$. MCP-1/CCR2 signaling was involved in human crescentic glomerulonephrtitis and murine lupus nephritis $[37,38]$. In a renal fibrosis model, the deletion of transient receptor potential vanilloid type 1 aggravated renal injury in salt-sensitive hypertension by enhancing MCP-1/CCR2 signaling-dependent inflammatory responses [39]. Blocking of CCR2 
Table 4: The association between MCP-1 -2518 and CCR2 +190 polymorphisms and clinical characteristics in IgAN patients

\begin{tabular}{|c|c|c|c|c|c|c|c|c|c|c|c|c|}
\hline $\begin{array}{l}\text { МCP-1 } \\
-2518\end{array}$ & \multicolumn{2}{|c|}{$\mathbf{A A} \mathbf{A B}+\mathbf{B B}$} & $P$ & $\begin{array}{c}\text { OR } \\
(95 \% \mathrm{CI})\end{array}$ & $\mathbf{A} \mathbf{A}+\mathbf{A} \mathbf{B}$ & BB & $P$ & $\begin{array}{c}\text { OR } \\
(95 \% \mathrm{CI})\end{array}$ & $\mathbf{A A}+\mathbf{B B}$ & $\mathbf{A B}$ & $P$ & $\begin{array}{c}\text { OR } \\
(95 \% \mathrm{CI})\end{array}$ \\
\hline \multicolumn{13}{|l|}{ Gender } \\
\hline Female & 45 & 50 & 0.95 & $0.98(0.60-1.62)$ & 95 & 26 & 0.92 & $0.97(0.57-1.67)$ & 71 & 50 & 0.99 & $1.00(0.64-1.56)$ \\
\hline Male & 86 & 94 & & & 180 & 48 & & & 134 & 94 & & \\
\hline \multicolumn{13}{|c|}{$24 \mathrm{~h}$ urine protein } \\
\hline$<3.5$ & 99 & 171 & 0.54 & $0.85(0.51-1.42)$ & 207 & 63 & 0.07 & $0.53(0.27-1.07)$ & 162 & 108 & 0.38 & $1.26(0.76-2.08)$ \\
\hline$\geq 3.5$ & 32 & 47 & & & 68 & 11 & & & 43 & 36 & & \\
\hline \multicolumn{13}{|c|}{ Blood pressure } \\
\hline$<140 / 90$ & 77 & 116 & 0.26 & $1.29(0.83-2.00)$ & 160 & 33 & 0.026 & $1.79(1.07-2.99)$ & 110 & 83 & 0.46 & $0.85(0.55-1.31)$ \\
\hline$\geq 140 / 90$ & 53 & 103 & & & 114 & 42 & & & 95 & 61 & & \\
\hline \multicolumn{13}{|c|}{ Lee's grade } \\
\hline I-III & 103 & 155 & 0.12 & $1.49(0.90-2.49)$ & 212 & 46 & 0.009 & $2.05(1.19-3.54)$ & 149 & 109 & 0.53 & $0.85(0.53-1.39)$ \\
\hline IV-V & 28 & 63 & & & 63 & 28 & & & 56 & 35 & & \\
\hline \multicolumn{13}{|c|}{ CCR2 +190 } \\
\hline \multicolumn{13}{|l|}{ Gender } \\
\hline Female & 73 & 49 & 0.69 & $1.09(0.70-1.71)$ & 112 & 10 & 0.68 & $0.84(0.37-1.92)$ & 83 & 39 & 0.52 & $1.16(0.73-1.86)$ \\
\hline Male & 132 & 97 & & & 213 & 16 & & & 148 & 81 & & \\
\hline \multicolumn{13}{|c|}{$24 \mathrm{~h}$ urine protein } \\
\hline$<3.5$ & 157 & 115 & 0.63 & $0.88(0.53-1.47)$ & 250 & 22 & 0.37 & $0.61(0.20-1.81)$ & 179 & 93 & 0.99 & $1.00(0.59-1.70)$ \\
\hline$\geq 3.5$ & 48 & 31 & & & 75 & 4 & & & 52 & 27 & & \\
\hline \multicolumn{13}{|c|}{ Blood pressure } \\
\hline$<140 / 90$ & 119 & 75 & 0.22 & $1.31(0.86-2.01)$ & 183 & 11 & 0.17 & $1.76(0.78-3.94)$ & 130 & 64 & 0.60 & $1.13(0.72-1.75)$ \\
\hline$\geq 140 / 90$ & 86 & 71 & & & 142 & 15 & & & 101 & 56 & & \\
\hline \multicolumn{13}{|c|}{ Lee's grade } \\
\hline I-III & 168 & 92 & $<0.001$ & $2.66(1.63-4.35)$ & 244 & 16 & 0.13 & $1.88(0.82-4.31)$ & 184 & 76 & 0.001 & $2.27(1.39-3.70)$ \\
\hline IV-V & 37 & 54 & & & 81 & 10 & & & 47 & 44 & & \\
\hline
\end{tabular}

A: the major allele; B: the minor allele; OR: odds ratio; 95\% CI: 95\% confidence interval

Table 5: The associations between MCP-1 -2518 and CCR2 +190 haplotypes and IgAN risk

\begin{tabular}{lccccc}
\hline $\mathbf{- 2 5 1 8}$ & $\mathbf{+ 1 9 0}$ & Controls & Cases & $\boldsymbol{P}$ & OR (95\%CI) \\
\hline $\mathrm{A}$ & $\mathrm{G}$ & 275 & 338 & & 1 \\
$\mathrm{~A}$ & $\mathrm{~A}$ & 267 & 264 & 0.07 & $0.80(0.64-1.02)$ \\
$\mathrm{G}$ & $\mathrm{A}$ & 78 & 100 & 0.81 & $1.04(0.75-1.46)$ \\
\hline
\end{tabular}

could improve the progressive fibrosis by decreasing macrophages in the diseased kidneys [40]. CCR2 gene is located in the region of chemokine receptor gene cluster and CCR2 is mainly produced by memory $\mathrm{T}$ cells, monocytes, dendritic cells, B cells and eosinophils. CCR2 +190 polymorphism is located at codon 64 of 
CCR2 gene with a single-nucleotide variation of $G$ to A. Under the stimulation of inflammation, CCR2 could increase the expression of MCP-1. Our study firstly investigated the relationship of CCR2 +190 polymorphism with IgAN risk and clinical parameters. The association between CCR $2+190$ polymorphism and Lee's grades was confirmed.

Compared with previous studies, we expand the sample size to 661 and performed the stratification analysis according to clinical characteristics in IgAN patients and the haplotype analysis to explore the interaction of the two polymorphisms. But several limitations exist in this study. Firstly, we only included 351 IgAN patients and 310 health controls, so the sample size may be small. Secondly, selection bias was inevitable. Thirdly, we only investigated the relationship in the Northwestern population, which is not on behalf of all areas.

In summary, we found an association between MCP-1 -2518 and IgAN patients' blood pressure and Lee's grades and an relationship between CCR2 +190 polymorphisms and Lee's grades, which suggested the two polymorphisms may affect the progression of IgAN. Therefore, more studies with larger sample size and different races are still needed to validate our study.

\section{MATERIALS AND METHODS}

\section{Ethics statement}

The study protocol was approved by the ethics committee of the Second Affiliated Hospital of Xi'an Jiaotong University. Written informed consent was obtained from all participants after a full explanation of the study. The experimental protocol was implemented in accordance with the approved guidelines.

\section{Subjects}

351 patients, which were diagnosed as IgAN by renal biopsy and non-familial IgAN cases, were enrolled from Northwestern China at the First and Second Affiliated Hospital of Xi' an Jiaotong University from March 2009 to April 2014. 310 healthy subjects were recruited from routine healthy examinations in the same hospitals. All subjects were unrelated Chinese Han people living in Xi'an city or nearby.
Patients would be excluded if they had comorbidities such as diabetes mellitus, lupus nephritis, and other secondary IgAN. Demographic and clinical details were collected, including age, gender, 24 hour urinenary protein, blood pressure, serum creatinine level (SCr), blood urea nitrogen (BUN), serum albumin level (ALB), serum cholesterol level (Cho), serum IgA level, serum C3 level, and histopathological grade (Lee's classification).

\section{DNA extraction and genotyping}

Blood samples were collected in tubes containing ethylene diaminetetraacetic acid (EDTA) and stored at $-80 \mathrm{C}$ after centrifugating at $1,500 \mathrm{rpm}$ for $10 \mathrm{~min}$. Genomic DNA from whole blood was extracted using the GoldMag DNA Purification Kit (GoldMag Co. Ltd, Xi'an City, China), and the purity and concentration was measured utilizing an ultraviolet spectrophotometer (Nanodrop, Thermo Scientific, Waltham, MA). The Sequenom MassARRAY Assay Design 3.0 software was used to design Multiplexed SNP MassEXTEND assay. SNP genotyping was performed by using Sequenom MassARRAY RS1000 according to the standard protocol. The primers used for MCP-1 -2518 and CCR2 +190 are listed in Table 6. Sequenom Typer 3.0 software was used for data analysis.

\section{Statistical analysis}

SPSS 18.0 statistical package was used for all the data analysis (SPSS, Chicago, IL, USA). The SNP frequency in the controls was assessed for departure from Hardy-Weinberg Equilibrium (HWE) using an exact test. An $\chi^{2}$ test was conducted for calculating allele and genotype frequencies of cases and controls. Odds ratios (ORs) and 95\% confidence intervals (CIs) were determined using unconditional logistic regression with adjustment for age and gender. Five genetic models (codominant, dominant, recessive, overdominant, and log-additive) were used to evaluate potential association of MCP-1 and CCR2 polymorphisms with risk and clinical parameters of IgAN. $P<0.05$ was considered statistically significant and all statistical tests were twosided.

Table 6: Primers used for this study

\begin{tabular}{llll}
\hline SNP-ID & 1st-PCRP & 2nd-PCRP & UEP_SEQ \\
\hline \multirow{2}{*}{ MCP-1-2518 } & ACGTTGGATGGAAG & ACGTTGGATGGGAG & AAGTCTTCT \\
& GTGAAGGGTATGAATC & GGCATCTTTTCTTGAC & GGAAAGTGA \\
\multirow{2}{*}{ CCR2 +190} & ACGTTGGATGTGTC & ACGTTGGATGTCTAC & GCAGTTTATT \\
& AGTCAAGCACTTCAGC & TCGCTGGTGTTCATC & AAGATGAGGA \\
\hline
\end{tabular}




\section{ACKNOWLEDGMENTS}

This work was supported by National Natural Science Foundation of China (No. 81470968, 81100530) and the Science and technology project of Shaanxi Province (2014K 11- 02- 04- 05)

\section{CONFLICTS OF INTEREST}

The authors have declared that no competing interest exists.

\section{REFERENCES}

1. Berger J, Hinglais N. [Intercapillary deposits of IgA-IgG]. J Urol Nephrol (Paris). 1968; 74: 694-5.

2. D'Amico G. The commonest glomerulonephritis in the world: IgA nephropathy. Q J Med. 1987; 64: 709-27.

3. Xie YX, He LY, Chen X, Peng XF, Ye MY, Zhao YJ, Yan WZ, Liu C, Shao J, Peng YM. Potential diagnostic biomarkers for IgA nephropathy: a comparative study preand post-tonsillectomy. Int Urol Nephrol. 2016. doi: 10.1007/ s11255-016-1372-2.

4. Ai Z, Xu R, Liu W, Zhou Q, Li B, Huang F, Yu X, Yang Q. Clinicopathologic features of IgA nephropathy patients with different levels of proteinuria. Clin Nephrol. 2016; 86: 35-41. doi: $10.5414 / \mathrm{cn} 108813$.

5. Xu X, Ning Y, Shang W, Li M, Ku M, Li Q, Li Y, Dai W, Shao J, Zeng R, Han M, He X, Yao Y, et al. Analysis of 4931 renal biopsy data in central China from 1994 to 2014. Ren Fail. 2016; 38: 1021-30. doi: 10.1080/0886022x.2016.1183443.

6. D'Amico G. Natural history of idiopathic IgA nephropathy and factors predictive of disease outcome. Semin Nephrol. 2004; 24: 179-96.

7. IgA nephropathy. Nat Rev Dis Primers. 2016; 2: 16002. doi: 10.1038/nrdp.2016.2.

8. Lomax-Browne HJ, Visconti A, Pusey CD, Cook HT, Spector TD, Pickering MC, Falchi M. IgA1 Glycosylation Is Heritable in Healthy Twins. J Am Soc Nephrol. 2016. doi: 10.1681/asn.2016020184.

9. Wang W, Li G, Hong D, Zou Y, Fei D, Wang L. Replication of genome-wide association study-identified 7 susceptibility genes affirms the effect of rs 2856717 on renal function and poor outcome of IgA nephropathy. Nephrology (Carlton). 2016. doi: 10.1111/nep.12860.

10. Wuttke M, Kottgen A. Insights into kidney diseases from genome-wide association studies. Nat Rev Nephrol. 2016. doi: 10.1038/nrneph.2016.107.

11. Mandal RK, Agrawal T, Mittal RD. Genetic variants of chemokine CCL2 and chemokine receptor CCR2 genes and risk of prostate cancer. Tumour Biol. 2015; 36: 375-81. doi: 10.1007/s13277-014-2646-x.
12. Tesch GH, Schwarting A, Kinoshita K, Lan HY, Rollins BJ, Kelley VR. Monocyte chemoattractant protein-1 promotes macrophage-mediated tubular injury, but not glomerular injury, in nephrotoxic serum nephritis. J Clin Invest. 1999; 103: 73-80. doi: 10.1172/jci4876.

13. Liu G, Wang H. Human albumin stimulates human renal tubular epithelial cells to produce monocyte chemoattractant protein-1. Chin J Nephrol. 2001: 394-8.

14. Sun Y, Yuan S, Xu X. [Expression of MCP-1 in renal tissues of patients with IgA nephropathy]. Zhong Nan Da Xue Xue Bao Yi Xue Ban. 2009; 34: 1023-8.

15. Kuper C, Beck FX, Neuhofer W. Autocrine MCP-1/ CCR2 signaling stimulates proliferation and migration of renal carcinoma cells. Oncol Lett. 2016; 12: 2201-9. doi: 10.3892/ol.2016.4875.

16. Wang Z, Xie H, Zhou L, Liu Z, Fu H, Zhu Y, Xu L, Xu J. CCL2/CCR2 axis is associated with postoperative survival and recurrence of patients with non-metastatic clear-cell renal cell carcinoma. Oncotarget. 2016; 7: 51525-51534. doi: 10.18632/oncotarget.10492.

17. Arakelyan A, Zakharyan R, Hambardzumyan M, Petrkova J, Olsson MC, Petrek M, Boyajyan A. Functional genetic polymorphisms of monocyte chemoattractant protein 1 and C-C chemokine receptor type 2 in ischemic stroke. J Interferon Cytokine Res. 2014; 34: 100-5. doi: 10.1089/jir.2013.0030.

18. Gao L, Tang H, Nie K, Wang L, Zhao J, Gan R, Huang J, Feng S, Zhu R, Duan Z, Zhang Y, Zhao X, Zhang Y, et al. MCP-1 and CCR2 gene polymorphisms in Parkinson's disease in a Han Chinese cohort. Neurol Sci. 2015; 36: 5716. doi: 10.1007/s10072-014-1990-3.

19. Nasibullin TR, Yagafarova LF, Yagafarov IR, Timasheva YR, Erdman VV, Tuktarova IA, Mustafina OE. Combinations of Polymorphic Markers of Chemokine Genes, Their Receptors and Acute Phase Protein Genes As Potential Predictors of Coronary Heart Diseases. Acta Naturae. 2016; 8: 111-6.

20. Zhou TB, Jiang ZP, Liang MJ, Huang YJ. Relationship between MCP-1 promoter $-2518 \mathrm{~A} / \mathrm{G}$ gene polymorphism (rs1024611) and systemic lupus erythematosus/lupus nephritis. J Recept Signal Transduct Res. 2015; 35: 85-93. doi: 10.3109/10799893.2014.931433.

21. Su N, Li HY, Huang MF, Jiang ZP, Zhou TB. Association of monocyte chemoattractant protein-1 2518G/A gene polymorphism with diabetic nephropathy risk. J Recept Signal Transduct Res. 2015; 35: 94-7. doi: 10.3109/10799893.2014.936458.

22. Nakajima K, Tanaka Y, Nomiyama T, Ogihara T, Piao L, Sakai K, Onuma T, Kawamori R. Chemokine receptor genotype is associated with diabetic nephropathy in Japanese with type 2 diabetes. Diabetes. 2002; 51: 238-42.

23. Mostowska M, Lianeri M, Oko A, Mostowska A, Jagodzinski PP. No association of monocyte chemoattractant protein-1 $-2518 \mathrm{~A} / \mathrm{G}$ polymorphism with the risk of primary 
glomerulonephritis in the Polish population. Mol Biol Rep. 2012; 39: 5933-41. doi: 10.1007/s11033-011-1405-y.

24. Rollins BJ. Chemokines. Blood. 1997; 90: 909-28.

25. Silva GE, Costa RS, Ravinal RC, Ramalho LN, Reis MA, Moyses-Neto M, Romao EA, Coimbra TM, Dantas M. Renal macrophage infiltration is associated with a poor outcome in IgA nephropathy. Clinics (Sao Paulo). 2012; 67: 697-703.

26. Guan F, Dong C, He M, Li J. Effects of rosiglitazone on the expressions of renal glomerulus NF-kB and AP-1 in mice with IgA nephropathy. ACTA ACADEMIAE MEDICINAE XUZHOU. 2010: 834-9.

27. Hua KF, Yang SM, Kao TY, Chang JM, Chen HL, Tsai YJ, Chen A, Yang SS, Chao LK, Ka SM. Osthole mitigates progressive IgA nephropathy by inhibiting reactive oxygen species generation and NF-kappaB/NLRP3 pathway. PLoS One. 2013; 8: e77794. doi: 10.1371/journal.pone.0077794.

28. Ashizawa M, Miyazaki M, Abe K, Furusu A, Isomoto H, Harada T, Ozono Y, Sakai H, Koji T, Kohno S. Detection of nuclear factor-kappaB in $\operatorname{IgA}$ nephropathy using Southwestern histochemistry. Am J Kidney Dis. 2003; 42: 76-86.

29. Pan Q. (2006). The significance of urine monocyte chemoattractant protein-1 in patients with IgA nephropathy. Guangxi Medical University).

30. Rovin BH, Yoshiumura T, Tan L. Cytokine-induced production of monocyte chemoattractant protein-1 by cultured human mesangial cells. J Immunol. 1992; 148: 2148-53.

31. Wang SN, LaPage J, Hirschberg R. Role of glomerular ultrafiltration of growth factors in progressive interstitial fibrosis in diabetic nephropathy. Kidney Int. 2000; 57: 100214. doi: 10.1046/j.1523-1755.2000.00928.x.

32. Stangou M, Bantis C, Skoularopoulou M, Korelidou L, Kouloukouriotou D, Scina M, Labropoulou IT, Kouri NM, Papagianni A, Efstratiadis G. Th1, Th2 and Treg/T17 cytokines in two types of proliferative glomerulonephritis. Indian J Nephrol. 2016; 26: 159-66. doi: 10.4103/0971-4065.159303.

33. Steinmetz OM, Panzer U, Harendza S, Mertens PR, Ostendorf T, Floege J, Helmchen U, Stahl RA. No association of the $-2518 \mathrm{MCP}-1 \mathrm{~A} / \mathrm{G}$ promoter polymorphism with incidence and clinical course of IgA nephropathy. Nephrol Dial Transplant. 2004; 19: 596-601.

34. Mori H, Kaneko Y, Narita I, Goto S, Saito N, Kondo D, Sato F, Ajiro J, Saga D, Ogawa A, Sakatsume M, Ueno M, Tabei $\mathrm{K}$, et al. Monocyte chemoattractant protein-1 A-2518G gene polymorphism and renal survival of Japanese patients with immunoglobulin A nephropathy. Clin Exp Nephrol. 2005; 9: 297-303. doi: 10.1007/s10157-005-0375-6.

35. Zhu Q, Zhu P, Zhang Y, Li J, Ma X, Li N, Wang Q, Xue X, Luo L, Li Z, Ring HZ, Ring BZ, Su L. Analysis of Social and Genetic Factors Influencing Heterosexual Transmission of HIV within Serodiscordant Couples in the Henan Cohort. PLoS One. 2015; 10: e0129979. doi: 10.1371/journal. pone.0129979.

36. Santos EU, Lima GD, Oliveira Mde L, Heraclio Sde A, Silva HD, Crovella S, Maia Mde M, Souza PR. CCR2 and CCR5 genes polymorphisms in women with cervical lesions from Pernambuco, Northeast Region of Brazil: a case-control study. Mem Inst Oswaldo Cruz. 2016; 111: 174-80. doi: 10.1590/0074-02760150367.

37. Segerer S, Cui Y, Hudkins KL, Goodpaster T, Eitner F, Mack M, Schlondorff D, Alpers CE. Expression of the chemokine monocyte chemoattractant protein-1 and its receptor chemokine receptor 2 in human crescentic glomerulonephritis. J Am Soc Nephrol. 2000; 11: 2231-42.

38. Perez de Lema G, Maier H, Nieto E, Vielhauer V, Luckow B, Mampaso F, Schlondorff D. Chemokine expression precedes inflammatory cell infiltration and chemokine receptor and cytokine expression during the initiation of murine lupus nephritis. J Am Soc Nephrol. 2001; 12: 1369-82.

39. Wang Y, Zhu M, Xu H, Cui L, Liu W, Wang X, Shen S, Wang $\mathrm{DH}$. Role of the monocyte chemoattractant protein-1/C-C chemokine receptor 2 signaling pathway in transient receptor potential vanilloid type 1 ablation-induced renal injury in salt-sensitive hypertension. Exp Biol Med (Maywood). 2015; 240: 1223-34. doi: 10.1177/1535370214565970.

40. Kitagawa K, Wada T, Furuichi K, Hashimoto H, Ishiwata Y, Asano M, Takeya M, Kuziel WA, Matsushima K, Mukaida N, Yokoyama H. Blockade of CCR2 ameliorates progressive fibrosis in kidney. Am J Pathol. 2004; 165: 237-46. doi: 10.1016/s0002-9440(10)63292-0. 